\title{
31. NOLLETIA CHRYSOCOMOIDES (DESF.) LESS. (COMPOSITAE), ESPECIE A EXCLUIR DE LA FLORA EUROPEA
}

\author{
Carlos AEDO
}

Recibido el 9 de septiembre de 2014, aceptado para su publicación el 23 de septiembre de 2014

Nolletia chrysocomoides (Desf.) Less. (Compositae), species to be excluded to the European flora

Palabras clave: Nolletia, corología, Europa.

Key words: Nolletia, chorology, Europe.

Nolletia chrysocomoides (Desf.) Less., Syn. Gen. Compos.: 187 (1832) [Conyza chrysocomides Desf., Fl. Atlant. 2: 269, tab. 232 (1799)] es una especie norteafricana que se encuentra desde el W de Libia a Marruecos y Mauritania --alcanza por el S el Hoggar en Argelia y quizás Níger- [Jafri \& El-Gadi (1983: 31); Ozenda (2004: 423)]. En el herbario del Real Jardín Botánico (MA) hay varios ejemplares norteafricanos en los que se aprecian bien las principales características de la especie. Es un sufrútice ramificado desde la base, con pelos tectores -aplicados y antrorsos- en tallos y hojas, hojas lineares de 8-13 mm de longitud y capítulos solitarios en el ápice de las ramas. Las brácteas del capítulo son lanceoladas, de unos $3 \mathrm{~mm}$ de longitud, dispuestas en tres filas por lo general y con un indumento no muy denso similar al de tallos y hojas. Los capítulos son pequeños, de unos 10-12 mm de diámetro. En la parte externa de estos se dispone una fila de flores filiformes, femeninas, amarillas. Los flósculos ocupan el resto del capítulo y son algo mayores, de 3-3,5 mm de longitud, hermafroditas, amarillos. Los aquenios son de 1,2-2,1 mm de longitud, obovoideos, comprimidos, con pelos adpresos, antrorsos, muy cortos, a lo sumo de $0,1 \mathrm{~mm}$. El vilano, que está formado por 18-25 pelos escábridos, es muy frágil y se cae rápidamente.

Willkomm (1865: 35) citó esta especie en la provincia de Málaga, concretamente "In regni Granat. regione calida rarissima (in Sierra Bermeja, Haens.!)... Jun. (v.s.)", localidad que constituiría la única europea conocida (Tutin \& al., 1976: 120). Tras esta mención nunca se ha vuelto a colectar por lo que se ha considerado que podría tratarse de una determinación errónea o bien una especie extinta en esa localidad [Cabezudo \& al. (1999: 204); Cabezudo \& al. (2004: 68)]. En el herbario de Willkomm, depositado en la universidad de Coímbra (COI), no se ha encontrado ningún ejemplar de Nolletia chrysocomoides. Por fortuna en el herbario de la universidad de Granada (GDA), donde se conservan las plantas de F. Haenseler -cedidas por la Sociedad Malagueña de Ciencias [Laza (1944), Pérez Rubín (2012)]-, ha aparecido el ejemplar al que se refiere Willkomm. En la etiqueta se lee "In Sierra Bermeja ad laterum maris" lo que permite aventurar que la planta fue colectada en cotas bajas, probablemente en un hábitat costero. Haenseler llegó a Málaga hacia 1803 y estuvo botánicamente activo hasta 1839, periodo en el que con toda probabilidad se colectó la planta. El mencionado pliego 
(GDA-4285) consta de una rama con tres capítulos en el extremo de sendas ramillas más un fragmento con hojas. Las hojas son mucho más largas que la de $N$. chrysocomoides (35-47 x 2,8-3,5 mm), estrechamente lanceoladas y cortamente pecioladas y con las características glándulas sésiles de Aster sedifolius L. Los capítulos son también mayores (15-16 mm de diámetro). A las tres filas de brácteas se añaden un conjunto de hojas bracteiformes del ápice de la ramilla que semejan un segundo involucro. Tallos, ramas y hojas carecen del característico indumento de $N$. chrysocomoides. Se ha abierto un capítulo y no se ha encontrado ninguna flor filiforme, solamente flósculos. Los aquenios, aunque no están completamente formados, son más largos (2,8-3 mm) y tienen un indumento muy denso constituido por pelos de $0,5-0,7 \mathrm{~mm}$. El vilano está compuesto por abundantes pelos escábridos, persistentes, de alrededor de $5 \mathrm{~mm}$. Este conjunto de caracteres permite rechazar la identificación de Willkomm (1865: 35) como $N$. chrysocomoides y como consecuencia excluir la planta de Europa. Desafortunadamente durante la preparación del catálogo de especies extintas de España (Aedo et al. 2014) tan solo se examinó una fotografía del pliego por lo que no se pudo hacer la rectificación que ahora se lleva a cabo. Tanto el involucro como las glándulas de las hojas sugieren que estamos ante un Aster L. del grupo de las "Galatellas". La falta de flores liguladas apuntaría a Aster linosyris (L.) Bernh. [Galatella linosyris (L.) Rchb. fil.], pero esta especie se puede excluir por sus hojas más estrechas y su sinflorescencia en pseudocorimbo denso. Queda tan solo la opción de asimilar esta muestra a Aster sedifolius L. [Galatella sedifolia (L.) Greuter], especie por lo común con flores liguladas, que en ocasiones presenta formas aliguladas. De esta especie se conocen varias localidades malagueñas, algunas de ellas con capítulos sin flores liguladas (G. Blanca, in litt.), aunque todas en cotas superiores a los 900 m (B. Cabezudo, in litt.).

\section{BIBLIOGRAFÍA}

AEDO, C., L. MEDINA, P. BARBERÁ \& M. FERNÁNDEZ-ALBERT -2014- Extinction of vascular plants in Spain. Nordic. J. Bot. (in press).

CABEZUDO, B., Y. GIL, D. NAVAS, P. NAVAS \& A. V. PÉREZ LATORRE -2004- Nolletia chrysocomoides (Desf.) Cass. ex Less in: BAÑARES, Á., G. BLANCA, J. GÜEMES, J.C. MORENO \& S. ORTIZ (EDS.) -2004- Atlas y libro rojo de la flora vascular amenazada. ed. 2. Pág. 68. Ministerio de Medio Ambiente, Madrid. CABEZUDO, B.,A. V.PÉREZLATORRE, P. NAVAS \& D. NAVA -1999-Nolletia chrysocomoides (Desf.) Cass. ex Less in: BLANCA, G., B. CABEZUDO, J.E. HERNÁNDEZ BERMEJO, C.M. HERRERA, J. MOLERO MESA, J. MUÑOZ \& B. VALDÉS (eds.). Libro rojo de la Flora Silvestre Amenazada de Andalucía, tomo 1: 203-205.

JAFRI, S.M.H. \& A. EL-GADI -1983- Flora of Libya 107. Trípoli.

LAZA, M. -1944- Estudios sobre la flora andaluza (conclusión). Anales Real. Acad. Farm. 10: 497-556.

OZENDA, P. -2004- Flore et végétation du Sahara. CNRS editions, París.

PÉREZ RUBÍN, J. - 2012- El naturalista y farmacéutico germano-español Félix Hänseler Teger (1780-1841) en la Málaga de su época. Acta Bot. Malacitana 37: 141-162.

TUTIN, T.G., V.H. HEYWOOD, N.A. BURGES, D.M. MOORE, D.H. VALENTINE, S.M. WALTERS \& D.A. WEBB (eds.) -1976- Flora europaea. vol. 5. Cambridge University Press.

WILlKOMM, H. M. \& , J. M. C. LANGE -1865-1870- Prodromus florae Hispanicae, Volumen II. Sumtibus E. Schweizerbart, Stuttgart.

Dirección del autor. Real Jardín Botánico, CSIC, Pl. de Murillo, 2, 28014 Madrid. aedo@rjb.csic.es 